\title{
An Analysis of Whatsapp Emoji in Business Interactions between a Malaysian SME and the Turkish Counterparts
}

\author{
Rohayah Kahar \& Hadina Habil \\ Language Academy, Faculty of Social Sciences and Humanities, Universiti Teknologi Malaysia, 81310 UTM \\ Johor Bahru, Johor, Malaysia
}

Submitted: 06/02/2020. Revised edition: 30/03/2020. Accepted: 30/05/2020. Published online: 30/06/2020

\begin{abstract}
Social media platforms such as Twitter, Whatsapp, and Instagram are widely used by individuals around the globe. Entrepreneurs are among those who use social media as their platforms in selling and marketing their items. Particularly in WhatsApp communication, there are various functions of emoji in social networking that offer various messaging features. The purposes of this study were to identify the usage of emoji in WhatsApp business interactions and to describe types of emoji employed among Malaysian Small and Medium enterprises (SME) and his Turkish counterparts. This study used Content Analysis to provide interpretations about the emoji found in conversational messages between the entrepreneurs in their business interactions. The findings revealed that the Malaysian participant was more technology savvy when it came to the use of emoji compared to his Turkish business counterparts. Thus, the WhatsApp emoji represents a non-verbal communication and other functions in business interaction. Based on the findings, this study recommends that the use of emoji should be encouraged among entrepreneurs and customers to create a cheerful and customer-friendly atmosphere. Additionally, WhatsApp features should be used by both businesses and consumers to promote business processes and help readers understand the meaning of their communications.
\end{abstract}

Keywords: Social media communication, emoji, business English as a lingua franca, business communication

\section{INTRODUCTION}

Social media are the common platforms used by people to communicate and interact with others. There are several social media applications such as Facebook, Instagram, Twitter and many more. Meanwhile, there are also a variety of social networking applications which are WhatsApp Messenger, Telegram and Facebook Messenger. WhatsApp application is one of the social network communications that is commonly used by users all over the world. According to Bouhnik \& Deshen (2014), WhatsApp can be defined as a messenger application with a variety of functions, such as text messages, images, audio files and web address links. Even though the conversations in WhatsApp and other social applications are mostly empowered by text, the use of emoji has also

*Correspondence to: Rohayah Kahar (email: rohayahkahar@utm.my) 
been widely used as they bring beneficial functions in communications. This study examined interactions between a Malaysian participant and his three business counterparts from Turkey. Thus, the aim of this paper is to report the findings of part of a larger study in relation to the use of emoji in WhatsApp conversations.

\section{LITERATURE REVIEW}

Social media can be defined as a community of Internet-based applications built on the ideological and technological foundations of Web 2.0 and allowing user-generated content to be produced and shared (Kaplan \& Haenlein, 2010; Gancho, 2017). According to Treem et al., (2016), scholars have developed classifications that describe different types of communication technologies in social media. For instance, Kaplan \& Haenlein, (2010 cited in Gancho, 2017) state that there are various types of online applications such as projects such as Wikipedia; blogs / micro-blogs such as Twitter; content communities such as YouTube; social networking sites such as Instagram and others. Consequently, social media are believed to play an important role in changing people's lifestyle and these platforms have become their daily routine. On the other hand, there is no specific definition of an entrepreneur since different scholars or researchers have different definitions of an entrepreneur (Pahuja \& Sanjeev, 2015). Originally, the word of entrepreneur comes from the French word "entreprendre," which means to take over, undertake, commit, take up, try (Wickham, 2006; Cicek, 2018). Oxford Learner's Dictionary (2019) defines an entrepreneur as a person who assumes the responsibility of business or businesses with the possibility of profit or loss. As an entrepreneur, he or she needs to be brave enough to take risk throughout the business process.

Social media such as Facebook, Whatsapp and Instagram are commonly used by people all over the world to get connected. Entrepreneurs are one of them who use social media as their platforms in selling and promoting their products. In addition, they offer a platform for entrepreneurs to grow and develop their brands (Park et al., 2017). Entrepreneurs can use various methods and techniques in selling their products and promoting their business. Hence, social media platform is one of the effective techniques employed as it brings many advantages to both entrepreneurs and customers. The social media platform has been successfully used by many businesses, start-ups, and individuals to either kickstart or expand their products and services (Intelligent Money, 2019). Shabbir et al. (2016) state that social media networks are company's gateways to gain profit and grow in the industry. The usage of social media as their marketing medium enable them in gaining more profit from their customers. Park et al. (2017) state that social media are often regarded as valuable tools for entrepreneurship as they allow entrepreneurs to easily identify business development changes and opportunities through network interactions and communications with peers. Social networks are seen as dynamic and changing from the moment that entrepreneurs come up with a business concept, form a new venture and expand it (Nowiński \& Rialp, 2015). 
The United States is one of the countries that is currently leading the global entrepreneurship. Based on the Global Entrepreneurship Index 2018, the United States is the world leader in entrepreneurship where the country was nominated as number one in the world and first in the North American region, ahead of their Canadian peers (Acs et al., 2018). Meanwhile in Malaysia, it is said that young entrepreneurs contribute a lot to Malaysian economic development. Young generations, particularly young people, have recently formed a large segment, representing 43 percent of Malaysia's total population (Ridzwan et al., 2017). Chik et al. (2015) state that fostering the involvement of young entrepreneurs can be a key contributor to the development of economic growth in Malaysia by looking at youth entrepreneurship as an advocate for the development of social and medium enterprises (SMEs). In short, entrepreneurs especially young entrepreneurs have become one of the important assets to support the economies of many countries.

One of the social media applications used is Whatsapp Messenger. Statista (2016) claims that in February 2016, current statistics put the usage of WhatsApp at one billion. It is a popular mobile application that offers smartphone an instant messaging service (Kumar \& Sharma, 2017). WhatsApp Messenger is defined as a proprietary, cross-platform instant messaging subscription service for smart phones and selected feature phones that communicate using the internet (Yeboah \& Ewur, 2014; Bouhnik \& Deshen, 2014; Alsanie, 2015). Various beneficial features of this application are useful for the users. It is a free-of-charge application where it allows users to freely send text messages to one another and users are not required to pay for a text sent via WhatsApp because the messages are sent through an internet data connection (Mefolere, 2016). Hence, it enables users to send and receive location, image, video, audio and text messages in real time to individuals and groups of friends at no cost (Whatsapp, 2020).

Emoji is adapted from Japanese word that is defined as "picture" and "letter" (Danesi, 2017). Emoji are "image characters" or pictographs that are famous and mostly used in WhatsApp Messenger (Annamalai \& Abdul, 2017). Hasan (2018) mentions that emoji can be named as a facial emotion, or as a combination of keyboard characters displayed together with a text message showing the mood of the user. Emoji can also be represented as graphic symbols or ideograms that display not only facial expression but also broader ideas and concepts (Novak et al., 2015). Furthermore, Tauch \& Kanjo (2016) states that WhatsApp Messenger has a set of 722 graphic representations of emoji, likes smiley, objects, animals, travel, occasions, food and drinks, countries and activities. All of these representations have different functions and purposes for the users to use in their conversations. Additionally, emoji delivers the meaning through visual similarities to physical objects such as smiling face, transportations and drinks, but how people interpret the meaning of the emoji is not well known (Miller et al., 2016). It is because different people have different ways of interpreting the meaning and not everyone will show how they understand the meaning from the emoji.

Emoji is also commonly used because it provides beneficial messaging functions. There are various functions of emoji and emoticon in social networking especially in WhatsApp communication. Some researchers have argued that emoji can indicate emotions, non-emotional meanings that are conventionally mapped to facial expressions or illocutionary force (Dresner \& Herring, 2010; Aull, 2019). Furthermore, Annamalai \& Abdul (2017) mention that emoji offers an extended range of emoticon capabilities by adding a wide range of characters whose connection to emotional states, such as rage or fear that can be seen in face-to-face communication but concealed in the text. Thus, most 
social media users utilise emoji to show how they truly feel and at some point they use the emoji to hide their real feelings.

Another function of emoji is its pragmatic functions. To be specific, one of the pragmatic functions is illocutionary force markers where the markers indicate how the users understand the message (Dresner \& Herring, 2010; Celia, 2017). For instance, a smile emoji might indicate that the comment is not only for happy emotion but also for other purposes that are hidden in the text. The other pragmatic functions of emoji are politeness strategy (Darics, 2010; Kavanagh, 2016) and facesaving strategies (Maíz-Arévalo, 2015). People are using emoji to stop face-threatening behaviour such as self-humiliation or controlling emotion (Dresner \& Herring, 2010; Aull, 2019). The other pragmatic function is that emoji act as a booster of group rapport (Walther \& D'Addario, 2001: Golato \& Taleghani-Nikazm, 2006; Li \& Yang, 2018). Emoji really helps in implementing a close relationship between people or groups where they can understand each other in terms of ideas, feelings and many more. Hence, various types of emoji may serve different pragmatic functions in different settings of communication (Li \& Yang, 2018).

With respect to taxonomy of emoji's pragmatic functions, Yus (2014) proposed an 8-function taxonomy of emoji where it is the widest and the most comprehensive coverage so far. The table below is the taxonomy of emoji functions:

Table 1 Taxonomy of Emoji - The Eight-Functions

\begin{tabular}{|l|l|}
\hline No. & \multicolumn{2}{|c|}{ The Functions } \\
\hline 1. & $\begin{array}{l}\text { To signal the propositional attitude underlying the utterance and difficult to identify without the assistance of } \\
\text { the emoticon }\end{array}$ \\
\hline 2. & To express a higher intensity of a propositional attitude that is already coded verbally \\
\hline 3. & To strengthen/reduce the illocutionary force of a speech act \\
\hline 4. & To counter the explicit content of the utterance (humor) \\
\hline 5. & To contradict the explicit content of the utterance (irony) \\
\hline 6. & $\begin{array}{l}\text { To add a feeling or emotion towards the utterance's propositional content (affective attitude toward the } \\
\text { utterance) }\end{array}$ \\
\hline 7. & $\begin{array}{l}\text { To add an emotion or feeling to the overall communicative act (feeling or emotion in parallel to the } \\
\text { communicative act) }\end{array}$ \\
\hline 8. & To communicate the strength of a feeling or emotion that was coded verbally \\
\hline
\end{tabular}

Emoji serves as a window on how participants in online social life show expertise in Internetbased conversation management ( $\mathrm{Li} \&$ Yang, 2018). Therefore, it depends on how people interpret and understand the meaning behind the emoji used. To conclude, various functions of emoji can be found in WhatsApp communication and other social media. 


\section{METHODOLOGY}

This study was based on interactions in a Business English as a Lingua Franca (BELF) environment. The participants consisted of non-native speakers (NNS) of English. There were four participants involved in this study who were a Malaysian SME and his three business counterparts from Turkey. The Malaysian participant was known as M1 and he was an entrepreneur specialising in apparel and tourism business. The business counterparts involved three Turkish nationals. One of them was a Turkish national residing in Malaysia (TA) and the other two were from Turkey and (TB and TC) currently doing online business through social media. Additionally, the data collection was done through social media posting. The social media employed in this study was WhatsApp. Participants' interactions in their WhatsApp messages were gathered. The duration of the conversations took place between one week and three months, depending on the swiftness of the responses by the participants. In analysing the data, Content Analysis was employed to make interpretations about the messages in the conversations. Firstly, the data obtained were coded according to participant's nationality, his counterpart and line of conversations in the WhatsApp messages. Later, these were segregated into categories based on the stages of De Vito's Five-Stage Model of Conversation (2014). These stages comprised (1) Opening; (2) Feedforward; (3) Business; (4) Feedback; (5) Closing. Interpretations were made based on the coded conversations and finally, conclusions were derived.

\section{FINDINGS AND DISCUSSION}

The findings from the study are shown in the following figures (Figure 1 to Figure 4). Based on Figure 1 , it could be seen that M1 utilised the grinning face with big eyes emoji as a cute-flippant opener of the conversation as well as exuding warmth to his counterpart. There was none from the Turkish.

In Figure 2, the interactions were taking place in the Business Stage. There were four types of emoji employed here namely, smiling, grinning face with big eyes, 2-thumbs-up and one thumbs-up. In this stage, emoji were mainly used by M1 while the Turkish counterparts did not have any.

The next stage which had emoji during the interactions was the Feedback Stage (Figure3). Here, the Turkish counterparts had more usage of emoji comprising one-thumbs-up and smiling face. On the contrary, M1 employed the use of tears of joy and beaming face with smiling eyes. Finally, in the Closing Stage (Figure 4), the Turkish only employed OK hand while M1 had one thumbs-up (2) and grinning face with big eyes (2). Thus, based on all the data, it can be deduced that M1 had more usage of WhatsApp emoji compared to the Turkish counterparts. 


\begin{tabular}{|l|l|l|l|l|l|l|l|l|l|}
\hline NO. & TYPES OF EMOJI & Ml & FQ & TA & FQ & TB & FQ & TC & FQ \\
\hline 1. & $\begin{array}{c}\text { Grinning face with } \\
\text { big eyes } \\
\text { (Cute-flippant } \\
\text { opener) }\end{array}$ & [\# MITAL1]. & 1 & NF & NF & NF & NF & NF & NF \\
\hline $\begin{array}{c}\text { Grinning face with } \\
\text { big eyes } \\
\text { TOTAL }\end{array}$ & [\#MlTAL4] & 1 & NF & NF & NF & NF & NF & NF \\
\hline & TOTA & & 2 & 0 & 0 & 0 & 0 & 0 & 0 \\
\hline
\end{tabular}

Legend:

Ml= Participant 1

$\mathrm{FQ}=$ Frequency

$\mathrm{TA}=$ Turkish $\mathrm{A}$

$\mathrm{TB}=$ Turkish $\mathrm{B}$

$\mathrm{TC}=$ Turkish $\mathrm{C}$

$\mathrm{NF}=$ Not Found

Figure 1 Usage of Emoji in Opening Stage between Ml and Turkish Counterparts

\begin{tabular}{|c|c|c|c|c|c|c|c|c|c|c|c|c|c|}
\hline NO. & $\begin{array}{l}\text { TYPES OF } \\
\text { EMOJI }\end{array}$ & M1 & FQ & TA & $\begin{array}{l}\mathrm{F} \\
\mathrm{Q}\end{array}$ & M1 & FQ & TB & FQ & M1 & FQ & $\mathrm{TC}$ & FQ \\
\hline 1. & $\begin{array}{l}\text { Smiling } \\
=\equiv\end{array}$ & $\mathrm{NF}$ & 0 & $\begin{array}{l}\text { [\#TA } \\
\text { L7] }\end{array}$ & 1 & NF & 0 & $\mathrm{NF}$ & 0 & $\mathrm{NF}$ & 0 & 0 & 0 \\
\hline 2. & $\begin{array}{l}\text { Grinning face } \\
\text { with two big } \\
\text { eyes } \\
\text { emoji }\end{array}$ & $\mathrm{NF}$ & 0 & $\mathrm{NF}$ & $\begin{array}{l}\mathrm{N} \\
\mathrm{F}\end{array}$ & $\begin{array}{l}\text { [\#M1T } \\
\text { BL4] } \\
{[\# M 1 T} \\
\text { BL5] }\end{array}$ & $\begin{array}{l}1 \\
1\end{array}$ & $\mathrm{NF}$ & NF & $\mathrm{NF}$ & 0 & 0 & 0 \\
\hline 3. & 2 thumbs-up & $\begin{array}{l}\text { [\#M1TAL7] } \\
\text { [\#M1TAL8] } \\
\text { [\#M1TAL12 }\end{array}$ & $\begin{array}{l}1 \\
1 \\
1\end{array}$ & $\mathrm{NF}$ & 0 & $\mathrm{NF}$ & 0 & $\mathrm{NF}$ & $\mathrm{NF}$ & $\mathrm{NF}$ & 0 & 0 & 0 \\
\hline 4. & 1 thumbs-up & $\mathrm{NF}$ & 0 & $\mathrm{NF}$ & & $\begin{array}{l}\text { [\#M1T } \\
\text { BL5] }\end{array}$ & 1 & $\mathrm{NF}$ & $\mathrm{NF}$ & $\begin{array}{l}\text { [\#M1TCL } \\
12]\end{array}$ & 1 & 0 & 0 \\
\hline & TOTAL & & 3 & 0 & 0 & & 3 & 0 & & 0 & 1 & 0 & 0 \\
\hline
\end{tabular}

Legend:

MI= Participant 1

$\mathrm{FQ}=$ Frequency $\quad \mathrm{TB}=$ Turkish $\mathrm{B}$

$\mathrm{TC}=$ Turkish $\mathrm{C} \quad \mathrm{TA}=$ Turkish $\mathrm{A}$

Figure 2 Usage of Emoji in Business Stage between M1 and Turkish Counterparts 


\begin{tabular}{|c|c|c|c|c|c|c|c|c|c|c|c|c|c|}
\hline NO. & $\begin{array}{l}\text { TYPES OF } \\
\text { EMOJI }\end{array}$ & M1 & FQ & TA & FQ & M1 & FQ & TB & FQ & M1 & $\mathrm{FQ}$ & TC & FQ \\
\hline 1. & Tears of joy & [\#MTAL16] & 1 & $\mathrm{NF}$ & 0 & $\mathrm{NF}$ & 0 & $\mathrm{NF}$ & 0 & $\mathrm{NF}$ & 0 & $\mathrm{NF}$ & 0 \\
\hline 2. & 1 thumbs- & $\mathrm{NF}$ & 0 & $\begin{array}{l}\text { [\#TAL25] } \\
\text { [\#TAL28] }\end{array}$ & $\begin{array}{l}1 \\
1\end{array}$ & $\mathrm{NF}$ & 0 & $\mathrm{NF}$ & 0 & $\mathrm{NF}$ & 0 & $\mathrm{NF}$ & 0 \\
\hline 3. & $\begin{array}{l}\text { Beaming face } \\
\text { with smiling } \\
\text { eyes }\end{array}$ & [\#MTAL19] & 1 & $\mathrm{NF}$ & 0 & $\mathrm{NF}$ & 0 & $\mathrm{NF}$ & 0 & $\mathrm{NF}$ & 0 & $\mathrm{NF}$ & 0 \\
\hline 4. & Smiling face & $\mathrm{NF}$ & 0 & [\#TAL28] & 2 & $\mathrm{NF}$ & 0 & [\#TBL20] & 1 & $\mathrm{NF}$ & 0 & $\mathrm{NF}$ & 0 \\
\hline & TOTAL & & 2 & & 4 & & & & 1 & & & & \\
\hline
\end{tabular}

\section{Legend:}

M1= Participant 1

$\mathrm{FQ}=$ Frequency

$\mathrm{TA}=$ Turkish A

$\mathrm{TB}=$ Turkish $\mathrm{B}$

$\mathrm{TC}=$ Turkish $\mathrm{C}$

Figure 3 Usage of Emoji in Feedback Stage between M1 and Turkish Counterparts

\begin{tabular}{|c|c|c|c|c|c|c|c|c|c|c|c|c|c|}
\hline NO. & $\begin{array}{l}\text { TYPES OF } \\
\text { EMOJI }\end{array}$ & M1 & FQ & TA & FQ & M1 & FQ & TB & FQ & M1 & FQ & TC & FQ \\
\hline 1. & $\begin{array}{c}\text { Grinning } \\
\text { face with big } \\
\text { eyes }\end{array}$ & $\begin{array}{l}\text { [\#MTAL20] } \\
{[\# \text { MTAL23] }}\end{array}$ & $\begin{array}{l}1 \\
1\end{array}$ & $\mathrm{NF}$ & 0 & $\mathrm{NF}$ & 0 & $\mathrm{NF}$ & 0 & $\mathrm{NF}$ & 0 & $\mathrm{NF}$ & 0 \\
\hline 2. & OK Hand & $\mathrm{NF}$ & 0 & [\#TAL29] & 1 & $\mathrm{NF}$ & 0 & $\mathrm{NF}$ & 0 & NF & 0 & $\mathrm{NF}$ & 0 \\
\hline 3. & 1 thumbs-up & $\begin{array}{l}\text { [\#MTAL } \\
21] \\
\text { [\#MTAL22] }\end{array}$ & $\begin{array}{l}1 \\
1\end{array}$ & $\mathrm{NF}$ & 0 & $\mathrm{NF}$ & 0 & $\mathrm{NF}$ & 0 & $\mathrm{NF}$ & 0 & $\mathrm{NF}$ & 0 \\
\hline & TOTAL & & 4 & & 1 & & & & & & & & \\
\hline
\end{tabular}

Legend:

Ml= Participant 1 TA= Turkish A TC= Turkish C

$\mathrm{FQ}=$ Frequency $\mathrm{TB}=$ Turkish

Figure 4 Usage of Emoji in the Closing Stage between M1 and Turkish Counterpart 
In interactions between Ml and TA, the data indicated that Ml used more emoji compared to TA. For instance, M1 used many thumbs-up emoji throughout the conversation to show agreement and approval towards TA statements. In this part, M1 used more non-verbal functions in face-to-face communication than TA. Furthermore, M1 showed more varied use of emoji compared to TA. This can be found in the data where a variety of emoji were being used by M1 during the interaction such as thumbs-up emoji, OK hand emoji, smiling emoji, grinning face with big eyes and many more. M1 used various emoji to enliven the conversation and make it as simple as possible. Therefore, Ml was considered more technology savvy when it came to the use of emoji. Moreover, M1 used pictures and forwarded message to start and reply the conversation. TA also used pictures and forwarded message like M1. Hence, both of them utilised WhatsApp features to the fullest. Overall, the Business Stage showed more emoji usage throughout the interaction between M1 and TA. Indeed, emoji serves to strengthen the meaning of sent messages so that the emotions can be felt by the receivers (Chairunnisa \& Benedictus, 2017).

In interactions between M1 and TB, the findings showed that not many emoji were found throughout the conversation. Additionally M1 used more emoji than TB but not as many as the communication between M1 and TA. It was found that from the data, TB only used one emoji which was smiling emoji. Besides that, TB used voice recording (WhatsApp feature) once in the conversation. From the findings, TB used the voice recording due to the late reply. Since TB was busy, instead of typing a long text, he recorded his voice to seek for forgiveness and give information needed by M1. It was more convenient to use voice recording to save more time. Further, TB used more photos compared to M1. Since TB was also an entrepreneur, he sent more pictures to promote products to M1. In short, the use of emoji in here was less compared to M1 and TA.

In interactions between M1 and TC, the findings show that there was only one emoji found throughout the conversation. There was only one emoji used by M1 which was thumbs-up emoji (in the Business Stage). TC did not use any emoji at all and this might be due to TC is not that technology savvy about the use of emoji. Furthermore, Ml used many pictures compared to TC in order to ask for more information about the product that TC is selling. For example, M1 was forwarding several photos and requesting for the availability of the items requested. In addition, M1 used pictures and forwarded message to start and reply the conversation. TC also used forwarded message to reply the questions from M1. Hence, both of them used WhatsApp features throughout the interaction. In brief, there was only one emoji used between Ml and TC was less used compared to the two previous Turkish counterparts (TA and TB).

There was a difference in the total number of interactions for each nationality. The total interactions for TA was higher than M1 where TA interacted 30 times while M1 was 23 times. In interactions between M1 and TB, TB interacted more than M1 in which the total number of interactions by TB was 49 while M1 was 24 times. However, in interactions between M1 and TC, M1 interacted more than TC where the total number of interactions for M1 was 16 while TC was 13. Additionally, the Business Stage had the highest frequency on the use of emoji in all stages. Overall, between M1 and TA, TB and TC, the use of emoji was employed but with different frequency. In short, M1 and TA used more emoji compared to his interactions between TB and TC. 


\section{CONCLUSION}

The usage of various emoji may facilitate the process of doing business among business entrepreneurs. The use of emoji helps both entrepreneurs and customers control and maintain the level of conversation to avoid any misunderstanding. Each emoji consists of different meaning and it depends on how the sender wants the reader to understand the meaning throughout the communication. In conclusion, WhatsApp emoji serves as a non-verbal communication in business interaction.

\section{RECOMMENDATIONS}

Based on the findings obtained, there are several recommendations for the study. Firstly, the use of emoji should be encouraged among entrepreneurs and customers to create a cheerful and customerfriendly atmosphere. Secondly, both entrepreneurs and customers should be skilful in using WhatsApp features to facilitate the business processes and help the readers understand the meaning in their communications. It is also suggested that for future studies on the use of emoji, the focus should be on more different nationalities. Lastly, future studies should also investigate the use of other features of WhatsApp other than the emoji in their business interactions.

\section{REFERENCES}

Acs, Z. \& Szerb, László \& Lafuente, Esteban \& Lloyd, A. 2018. The Global Entrepreneurship Index 2018. UK: Springer.

Alsanie, S. I. 2015. Social Media (Facebook, Twitter, WhatsApp) Used, and it's Relationship with the University Students Contact with their Families in Saudi Arabia. Universal Journal of Psychology. 3(3): 69-72.

Annamalai, S. \& Abdul S. S. 2017. Undergraduates' Interpretation on WhatsApp Smiley Emoji. Jurnal Komunikasi, Malaysian Journal of Communication. 33: 89-103.

Aull, B. 2019. A Study of Phatic Emoji Use in WhatsApp Communication. Internet Pragmatics.

Bouhnik, D. \& Deshen, M. 2014. WhatsApp Goes to School: Mobile Instant Messaging between Teachers and Students. Journal of Information Technology Education:Research. 13: 217-231.

Célia S. 2017. The Interplay of Emoji, Emoticons, and Verbal Modalities in CMC: A Case Study of YouTube Comments. VINM: Visualizing (in) the New Media, Neuchâtel, Switzerland. Conference Paper.

Chairunnisa, S. \& Benedictus, A. S. 2017. Analysis of Emoji and Emoticon Usage in Interpersonal Communication of Blackberry Messenger and WhatsApp Application User. Int. J. Soc. Sc. Manage. 4 (2): 120-126.

Chik, R. \& Wahab, I. \& Zarina, Salleh \& Abdul K., Mohd A. B. \& Rohana, Ngah \& Marzuki, Sharifah \& Buyong, Siti \& Rosly, Hardi \& Junid, J. 2015. New Gen Entrepreneurship in 
Malaysia: A Vibrant Economic Force. Retrieved from Research Gate on 20 November 2020. Cicek, B. 2018. Social Media Entrepreneurship. İçtimaiyat Sosyal Bilimler Dergisi. 2.

Danesi, M. 2017. The Semiotics of Emoji: The Rise of Visual Language in the Age of the Internet. London: Bloomsbury Publishing Plc.

Darics, E. 2010. Politeness in Computer-mediated Discourse of a Virtual Team. J Politeness Res. 6(1): 129-150.

De Vito, J. A. 2014. The Interpersonal Communication Book. USA: Pearson.

Dresner, E. \& Herring, S. C. 2010. Functions of the Nonverbal in CMC: Emoticons and Illocutionary Force. Communication Theory. 20(3): 249-268.

Gancho, S. 2017. Social Media: A Literature Review. e-Revista LOGO. 6: 1-20.

Golato, A., \& Taleghani-Nikazm, C. 2006. Negotiation of Face in Web Chats. Multilingua-Journal of Cross-Cultural and Interlanguage Communication. 25(3): 293-321.

Hasan, A. F. 2018. The Role of Emoji and Emoticons in Enhancing Interpersonal Communication through Messenger and WhatsApp Applications. Adab Al-Kufah. 2(37): 115-130.

Intelligent Money. 2019. 3 Entrepreneurs Who Used Instagram to Take It to the Next Level. Retrieved from https:/www.imoney.my/articles/malaysian-entrepreneurs-instagram on December 30, 2019.

Kavanagh, Barry. 2016. Emoticons as a Medium for Channeling Politeness within American and Japanese Online Blogging Communities. Language \& Communication. 48: 53-65.

Kaplan, A. \& Haenlein, M. 2010. Users of the World, Unite! The Challenges and Opportunities of Social Media. Business Horizons. 53(1): 59-68.

Kumar, N. \& Sharma, S. 2017. Survey Analysis on the Usage and Impact of Whatsapp Messenger. Global Journal of Enterprise Information System. 8: 52.

Li, L. \& Yang, Y. 2018. Pragmatic Functions of Emoji in Internetbased Communication---A CorpusBased Study. Asian-Pacific Journal of Second and Foreign Language Education. 16(3): https://doi.org/10.1186/s40862-018-0057-z.

Maíz-Arévalo, C. 2015. Typographic Alteration in Formal Computermediated Communication. Procedia-Social and Behavioral Sciences. 212: 140-145.

Mefolere, K.F. 2016. WhatsApp and Information Sharing: Prospect and Challenges. International Journal of Social Science and Humanities Research. 4(1): 615-625.

Miller, J., Thebault-Spieker, J., Chang, S., Johnson, I., Terveen, L., \& Hecht, B. 2016. "Blissfully Happy" or "Ready to FIght": Varying Interpretations of Emoji. Proceedings of the 10th International Conference on Weblogs and Social Media 259-268. Cologne, Germany.

Novak, P. K., Smailović, J., Sluban, B. \& Mozetič, I. 2015. Sentiment of Emoji. Plos One. 10(12): e0144296.

Nowiński, W. \& Rialp, A. 2015. The Impact of Social Networks on Perceptions of International Opportunities. Journal of Small Business Management. doi: 10.1111/jsbm.12149.

Oxford Learner's Dictionary. 2019. Definition of Entrepreneur. Retrieved on 20 November 2019 from https://www.oxfordlearnersdictionaries.com/definition/english/entrepreneur.

Pahuja, A. \& Sanjeev, R. 2015. Introduction to Entrepreneurship. Retrieved on 10 November 2019 from https://ssrn.com/abstract $=2761878$. 
Park, J. Y., Sung, C. S. \& Im, I. 2017. Does Social Media Use Influence Entrepreneurial Opportunity? A Review of its Moderating Role. Sustainability. 9: 1593. doi:10.3390/su9091593

Ridzwan, R. \& Muhammad, N. \& Ab Rahman, A. 2017. Issues and Challenges among Young Entrepreneurs in Malaysia. IOSR Journal of Business and Management. 19: 80-84.

Shabbir, M., Ghazi, M. \& Mehmood, A. 2016. Impact of Social Media Applications on Small Business Entrepreneurs. Arabian Journal of Business and Management Review. 6(3): 1-4.

Statista. 2019. Facebook: Number of Monthly Active Users Worldwide 2008-2019. Retrieved on 19 November 2019 from https:/www.statista.com/statistics/264810/number-of-monthly-activefacebook-users-worldwide/.

Tauch, C. \& Kanjo, E. 2016. The Roles of Emoji in Mobile Phone Notifications. Proceedings of 2016 ACM International Joint Conference on Pervasive and Ubiquitous Computing, Germany. 15601565.

Treem, J. W., Dailey, S. L., Pierce, C. S., Biffl, D. 2016. What we are Talking about When We Talk about Social Media: A Framework for Study. Sociology Compass. 10: 768-784.

Walther, J. B. and D'Addario, K. P. 2001. The Impacts of Emoticons on Message Interpretation in Computer-mediated Communication. Social Science Computer Review. 19: 324-347.

Whatsapp. 2020. Retrieved on 20 January 2020 from https://www.whatsapp.com/.

Wickham, P. A. 2006. Strategic Entrepreneurship. USA: Pearson Education.

Yeboah, J. \& Ewur, G. 2014. The Impact of WhatsApp Messenger Usage on Students Performance in Tertiary Institutions in Ghana. Journal of Education and Practice. 5: 157-164.

Yus, F. 2014. Not All Emoticons are Created Equal. Linguagem em (Dis)curso. 14(3): 511-529. 